\title{
Article \\ Effect of Sulfur Content on the Inclusion and Mechanical Properties in Ce-Mg Treated Resulfurized SCr420H Steel
}

\author{
Meng Sun ${ }^{1}$, Zhouhua Jiang ${ }^{1,2, *}$, Yang $\mathrm{Li}^{1}{ }^{1 *}$, Changyong Chen ${ }^{3}$, Shuai Ma ${ }^{1}$, Yongshuai $\mathrm{Ji}^{1}{ }^{1}, \mathrm{Ju}$ Wang ${ }^{1}$ \\ and Hang Liu ${ }^{4}$
}

Citation: Sun, M.; Jiang, Z.; Li, Y.; Chen, C.; Ma, S.; Ji, Y.; Wang, J.; Liu, H. Effect of Sulfur Content on the Inclusion and Mechanical Properties in Ce-Mg Treated Resulfurized SCr420H Steel. Metals 2022, 12, 136. https://doi.org/10.3390/ met12010136

Academic Editor: Yanling Zhang

Received: 23 November 2021

Accepted: 7 January 2022

Published: 11 January 2022

Publisher's Note: MDPI stays neutral with regard to jurisdictional claims in published maps and institutional affiliations.

Copyright: (C) 2022 by the authors. Licensee MDPI, Basel, Switzerland. This article is an open access article distributed under the terms and conditions of the Creative Commons Attribution (CC BY) license (https:// creativecommons.org/licenses/by/ $4.0 /)$.
1 School of Metallurgy, Northeastern University, Shenyang 110819, China; 1810517@stu.neu.edu.cn (M.S.); mashuai2408@gmail.com (S.M.); 2001535@stu.neu.edu.cn (Y.J.); 2071604@stu.neu.edu.cn (J.W.)

2 State Key Laboratory of Rolling and Automation, Northeastern University, Shenyang 110819, China

3 School of Materials and Metallurgy, Wuhan University of Science and Technology, Wuhan 430081, China; cychen@wust.edu.cn

4 Institute of Metal Research, Chinese Academy of Sciences, Shenyang 110016, China; liuhang@imr.ac.cn

* Correspondence: jiangzh@smm.neu.edu.cn (Z.J.); liy@smm.neu.edu.cn (Y.L.)

\begin{abstract}
To clarify the effect of sulfur on inclusions and mechanical properties of Ce-Mg treated resulfurized SCr420H steel. Laboratory experiments were conducted to prepare steels with sulfur contents as $0.01 \%, 0.06 \%$, and $0.132 \%$. Inclusion evolution in liquid steel, MnS precipitation during solidification, and tensile test results of steel after quenching and tempering were investigated. The results showed that due to the limitation of mass transfer in molten steel, composite inclusion that CeO-S wrapped by Ce-Ca-Mg-Al-Si-O, which was named transition state inclusions, can form quickly after adding Ce-Mg lump to the molten steel. As the homogenization of molten steel, the difference of sulfur content in steel can lead to the transition state inclusions transformed into different inclusions. With the increase of sulfur content, the quantity of MnS increased significantly, and the morphology of MnS transformed from "stick" to "dendritic + fishbone", and then to "fishbone". Tensile test results and fracture analysis indicate that the decline of inclusion spacing as the increase of sulfur content leads to a shorter physical path of crack propagation in steel. Therefore, the increase of sulfur content can bring about a decrease in the strength and plasticity of the steel. From the perspective of inclusion control, making the MnS inclusion precipitate more dispersive and increasing the distance between inclusions can be considered as a method for preventing the decline of mechanical properties in steel with high sulfur content.
\end{abstract}

Keywords: MnS; inclusion; cerium; sulfur; fracture

\section{Introduction}

As an element that can improve steel machinability, sulfur has been widely used in gear steel, non-quenched and tempered steel, and other steel grades that require good turning and forming performance [1,2]. The increase of sulfur content can result in the formation of a large amount of $\mathrm{MnS}$ in steel. This inclusion can play a lubricating role during machining, reducing tool wear and machining costs [3-5]. Resulfurized gear steel SCr420H produced by a steel plant in China is a steel grade with sulfur addition (0.01-0.02\%), was widely used in the manufacture of high-grade automobile gears. The production process was as follows: electric arc furnace (EAF) $\rightarrow$ ladle furnace (LF) $\rightarrow$ vacuum degassing furnace (VD) $\rightarrow$ continuous casting (CC). During the production process, sulfur addition was conducted at the final timing of the VD process. Due to the lack of machinability, it is considered to design an enhanced machinability gear steel based on steel $\mathrm{SCr} 420 \mathrm{H}$ with increasing sulfur addition. In addition, to achieve grain refinement during the gear carburizing process [6,7], grain refining elements cerium and magnesium are considered to be added into steel during the secondary refining process [8-16]. However, it is known 
that sulfur, as one of the common inclusion forming elements, can participate in inclusion formation in liquid steel $[17,18]$ and MnS precipitation during solidification [19] and present an impact on the mechanical properties of steel finally [20]. Therefore, an in-depth understanding of the influence of sulfur content on inclusions and mechanical properties becomes necessary for designing a proper sulfur content for industrial production.

In recent years, the effect of cerium and magnesium in steel has gradually become a research hotspot, and many studies have reported that cerium and magnesium can improve the cleanliness and properties of steel [21-27]. However, the application of these two elements in industrial production has some limitations. High cerium content can easily cause nozzle clogging [28], and magnesium treatment have problems such as low yield and severe reaction [29]. Under this background, $\mathrm{Ce}-\mathrm{Mg}$ combined treatment technology has attracted the interest of scholars. This technology's idea is to realize cerium and magnesium's synergistic effect and avoid a high single element content addition. At present, this technology has been applied in the industrial processing of die steel for improving its performance [30]. As the elements with strong reactivity, cerium and magnesium can obviously impact inclusion in steel [31-37]. Li et al. [35] studied that the effect of Ce-Mg alloy on inclusion evolution in industrial production of die steel, and they found that with the increase of magnesium content, the stability area of cerium inclusions moves from the $\mathrm{Ce}_{2} \mathrm{O}_{2} \mathrm{~S}$ stability area to the direction of the CeS stability area. The literature [36] indicates that rare earth magnesium alloy has better deoxidization and desulfurization ability than only adding cerium and only adding $\mathrm{Mg}$ in $\mathrm{H} 13$ steel, because the composite inclusions that low-density $\mathrm{MgO}$ attaching or wrapping on the surface of high-density cerium inclusions are easy to float up. Chang et al. [37] found that inclusions in GCr15 bearing steel were obviously refined after rare earth (cerium and lanthanum) and magnesium treatment, and the proportion of large particle inclusions decreases with increasing rare earth content. It is noted that some studies clarified the relations between the content of rare earth element and magnesium and inclusion evolution, but it is rarely seen that research about the role of sulfur content in inclusion formation and evolution after $\mathrm{Ce}-\mathrm{Mg}$ treated steel.

As mentioned, MnS inclusion can enhance machinability as the free-cutting phase in steel. However, the mechanical properties of steel can inevitably be damaged, which is contradictory to the requirement of gear steel to have enough strength and plasticity. Many studies have studied the harmful effect of MnS inclusion in steel, but these researches mainly focus on steel with low sulfur content [38-41]. In resulfurized steel, the relation between MnS precipitation and fracture in steel with high sulfur content is needed to research, especially it may be different from steel with low sulfur content, due to the variety of morphology, quantity, and distribution of MnS.

In the present study, the industrial production process of resulfurized $\mathrm{SCr} 420 \mathrm{H}$ was simulated in laboratory. Three groups of steels with different sulfur content were prepared for comparison. Cerium and magnesium were added to the liquid steel during the refining process, and the influence of sulfur content on inclusion evolution was analyzed by sampling. The three-dimensional morphologies of $\mathrm{MnS}$ inclusion were revealed by the method of electrolytic etching. Based on the tensile test results and fracture observation, the relation between MnS inclusion and steel fracture was proposed.

\section{Methods}

\subsection{Material Preparation}

In this experiment, cerium and magnesium powder were mixed evenly and then pressed into a lump by using a powder compressing machine. The metal ratio was $(5 \%$ Ce-20\% Mg-75\% Fe), and the addition amount in the experiment was set as $0.7 \%$. Chemical reagents (Sinopharm Chemical Reagent Co., Ltd., Shanghai, China) were used to prepare refining slag, and all reagents were heated at $800^{\circ} \mathrm{C}$ for $6 \mathrm{~h}$ to remove moisture. To simulate the actual production situation, graphite, ferrosilicon, ferromanganese, chromium, nickel, copper, and molybdenum supplied by a domestic steel plant were used as alloy materials in this experiment, and $\mathrm{MgO}$ crucible was used as the reaction vessel (Shandong Refractories 
Group Lunai Kiln Refractory Co., Ltd., Shandong, China). The MgO crucible has a height of $90 \mathrm{~mm}$ and a diameter of $55 \mathrm{~mm}$. The total mass of experimental raw materials was controlled at about $1000 \mathrm{~g}$.

\subsection{Experiment Procedure}

Three experimental steels with different sulfur content were designed, each named Steel A, Steel B, and Steel C. Sulfur was added in steel in the form of FeS, and the addition of sulfur in the experiment was designed as 150 ppm, 700 ppm, and 1500 ppm, respectively. The experiment was conducted in a $\mathrm{MoSi}_{2}$ tube furnace, as shown in Figure 1. To control the air tightness of furnace, a simple air tightness inspection device was installed at the outlet of the furnace. During the whole experiment, $99.999 \%$ of high purity argon was continuously introduced into the furnace to control the protective atmosphere. The $\mathrm{MgO}$ crucible was placed in a graphite crucible, and the role of graphite crucible was to protect $\mathrm{MgO}$ crucible. The flow chart of the experiment was shown in Figure 2. The total time of the experiment was controlled at $73 \mathrm{~min}$. Before the experiment began, the molybdenum rod was used to stir the molten steel several times to ensure that the molten steel was completely liquid and uniform. At $5 \mathrm{~min}, \mathrm{Al}$ was fixed in the bottom of quartz tube and inserted in the molten steel during experiments. Refining slag (55\% $\mathrm{CaO} 11 \% \mathrm{SiO}_{2} 29 \%$ $\mathrm{Al}_{2} \mathrm{O}_{3} 5 \% \mathrm{MgO}$ Basicity $\mathrm{R}=5$ ) was added at 13 min of the experiment. At $48 \mathrm{~min}$, the refining process enters the second stage. Slag with high $\mathrm{SiO}_{2}$ content was added on steel for the purpose of adjusting the slag basicity to 1.5. At $53 \mathrm{~min}$, FeS wrapped by iron foil was fixed in the bottom of quartz tube and inserted in the molten steel. In order to ensure the yield, Ce-Mg lump is usually added at about 5-15 min before the end of steelmaking in production, and this design was referred to in the current experiment. Ce-Mg lump was added in liquid steel after FeS addition for $5 \mathrm{~min}$. At $73 \mathrm{~min}$, experiments were finished and started cooling. To understand the evolution behavior of inclusions in an experiment, quartz tubes with an internal diameter of $6 \mathrm{~mm}$ were used to extract the sample. Sample S0 was obtained at 58 min (timing before Ce-Mg lump addition), sample S1 was obtained at $60 \mathrm{~min}$ (timing after Ce-Mg lump addition for $2 \mathrm{~min}$ ), and sample S2 was cut from the as-cast ingot. In order to ensure the validity of experimental data, the first group experiment (Steel A) was repeated.

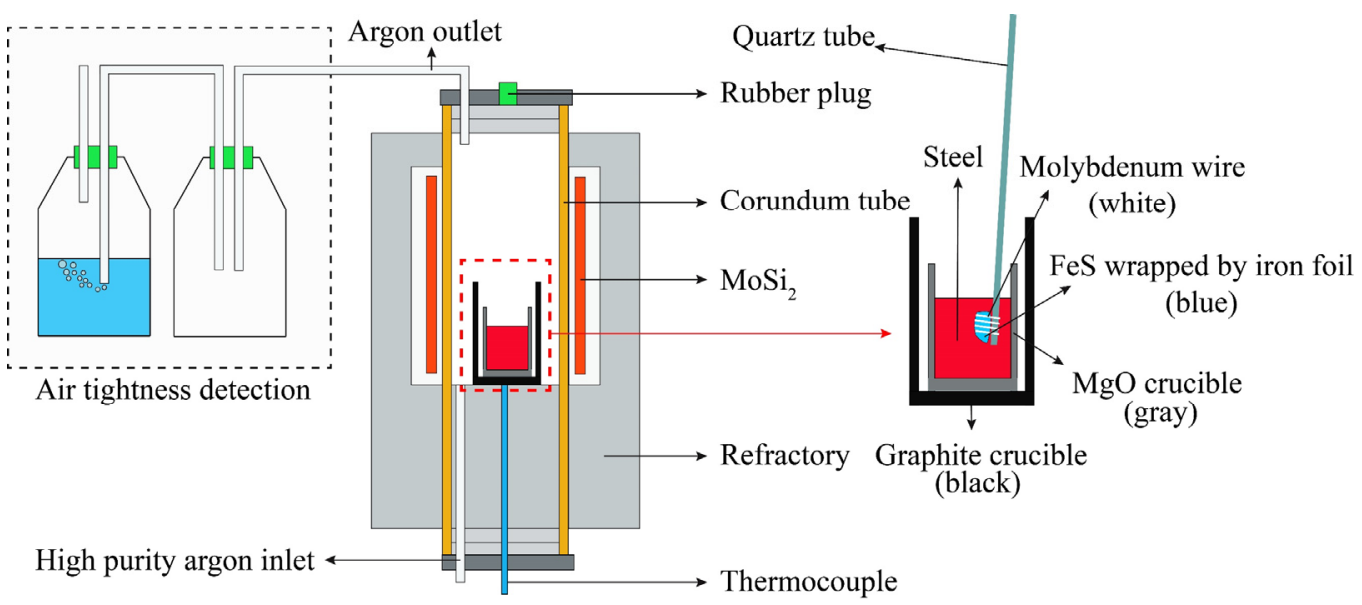

Figure 1. Sketch of experimental setup. 


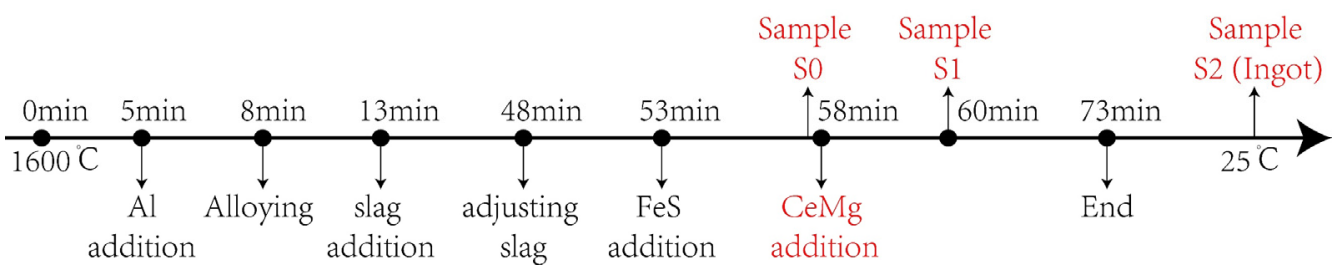

Figure 2. Experimental process.

The sample treatment method for inclusion observation and mechanical properties was shown in Figure 3. The cylindrical ingot was cut into two semi-cylinders along diameter. One was forged and conducted heat treatment for tensile test, and another was used to acquire samples for inclusion observation. The forging process starts at $1200^{\circ} \mathrm{C}$ after heat preservation for $2 \mathrm{~h}$, and finally air-cooled to room temperature after forging. The cross section of forging bar was $12 \mathrm{~mm} \times 12 \mathrm{~mm}$. Forged steel were austenized at $900{ }^{\circ} \mathrm{C}$ for $25 \mathrm{~min}$, and oil quenched to room temperature, followed by tempering at $200{ }^{\circ} \mathrm{C}$ for $120 \mathrm{~min}$. The atmosphere of heat treatment process was air. For the mechanical property characterization, tensile tests were conducted on Shimadzu AGS-X100KN electronic tensile testing machine following standard GB/T 228.1-2010 (ISO 6892-1:2009, MOD).

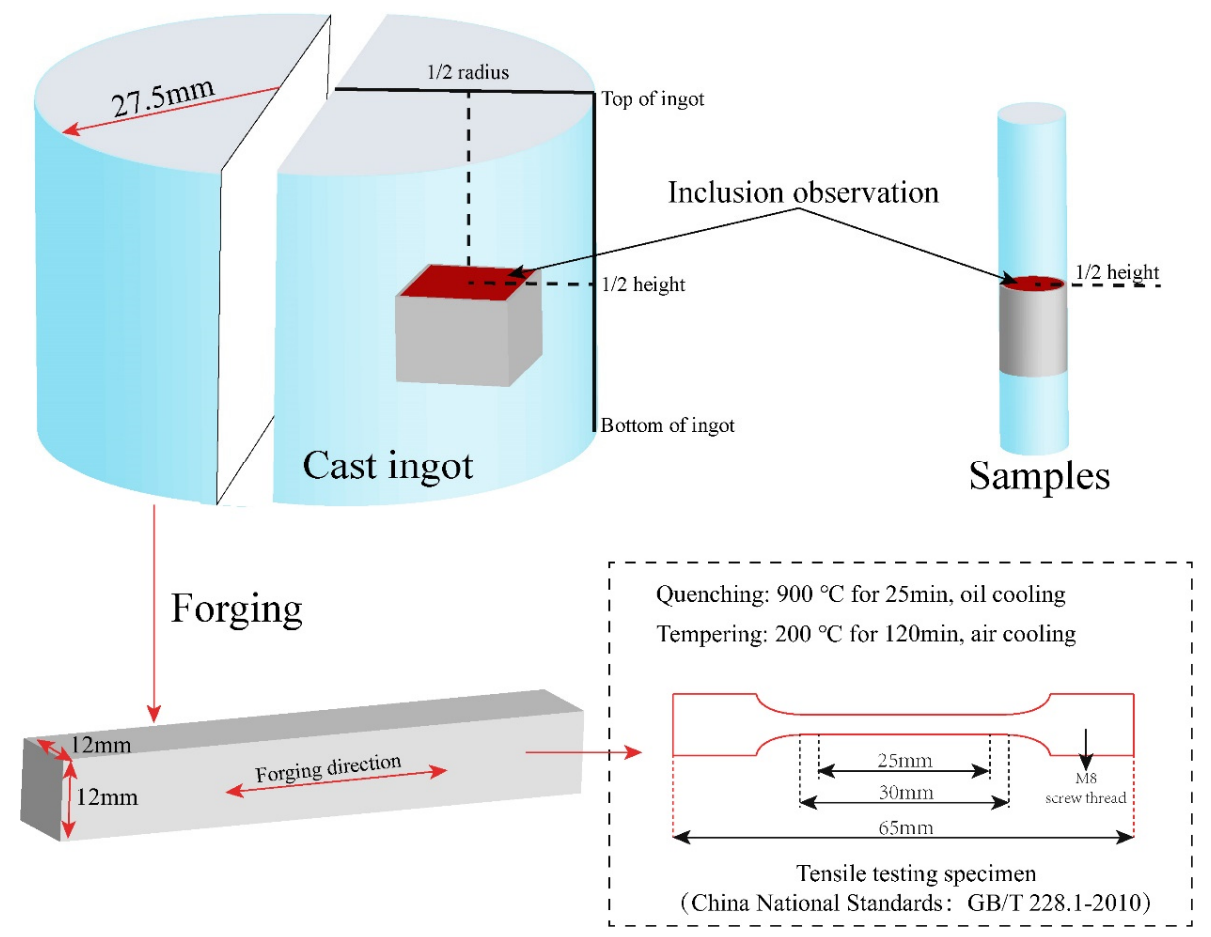

Figure 3. Sample treatment method for inclusion observation and mechanical properties.

\subsection{Analysis}

The as-cast sample was used to measure the steel composition. The contents of silicon, manganese, molybdenum, chromium, nickel and copper were measured by a direct reading spectrometer (ARL4460, Thermo Fisher Scientific, Waltham, MA, USA). The contents of carbon and sulfur were measured by infrared carbon and sulfur analyzer (CS230, LECO Corporation, St. Joseph, MI, USA), the contents of cerium and acid solution aluminum were measured by ICP-OES (Optima 8300DV, PerkinElmer, Waltham, MA, USA), The content of magnesium was measured by ICP-MS (Agilent 7800, Agilent Technologies, Santa Clara, CA, USA), and the content of oxygen was measured by nitrogen \& oxygen analyzer (ONH836, LECO Corporation, St. Joseph, MI, USA). 
ZEISS EVO18 SEM-EDS (Carl Zeiss AG, Oberkochen, Germany) was used to analyze the morphology and composition of inclusions in steel, and the OPTON OTSInca system (OTSInca, OPTON Co., Ltd., Beijing, China) was used to analyze density, aspect ratio, and $D_{\text {inclusion spacing }}\left(D_{\text {inclusion spacing }}\right.$ represents the average distance between each inclusion and its nearest inclusion) of inclusions in the steel. In order to reveal the three-dimensional morphology of MnS inclusions, the samples were electrolytically etched in $1 \%$ tetramethylammonium chloride-10\% acetylacetone-methanol [42], and the morphology was observed by SEM-EDS. FactSage 8.0 software (FactSage, Thermfact Ltd. (Montreal, QC, Canada) \& GTT-Technologies (Aachen, Germany)) was used to analyze the formation of inclusions in liquid steel at $1873 \mathrm{~K}$ and the precipitation of MnS during solidification. ZEISS ULTRA PLUS SEM-EDS (Carl Zeiss AG, Oberkochen, Germany) was used to analyze the surface and longitudinal section of the tensile fracture.

\section{Results and Discussion}

\subsection{Steel Composition}

The steel composition of Steel A-C was listed in Table 1, the yield of main alloy elements was stable. The sulfur content of Steel A-C was $0.01 \%, 0.06 \%$ and $0.132 \%$, and represented low sulfur, medium sulfur and high sulfur respectively. It can be seen that the yield of sulfur of Steel A-C was $66.7 \%, 85.7 \%$ and $88 \%$, respectively. As the increase of sulfur content, cerium content and magnesium content have a weak downward trend, but it can still be considered as the same level. In order to simulate production, ferroalloy used in the factory was used in this experiment, and calcium may come from calcium impurities in ferroalloy, which was illustrated in some literature [43,44].

Table 1. Steel composition (\%).

\begin{tabular}{ccccccccccccccccc}
\hline Steel & C & Si & Mn & Cr & Ni & Cu & Mo & Als & Ca & Mg & Ce & T.O & S & Category \\
\hline A & 0.191 & 0.320 & 0.865 & 1.210 & 0.16 & 0.17 & 0.03 & 0.020 & 0.0019 & 0.0010 & 0.014 & 0.0026 & 0.01 & Low sulfur \\
B & 0.203 & 0.298 & 0.872 & 1.210 & 0.15 & 0.17 & 0.03 & 0.017 & 0.0022 & 0.0009 & 0.013 & 0.0029 & 0.06 & Medium sulfur \\
C & 0.214 & 0.313 & 0.869 & 1.225 & 0.15 & 0.17 & 0.03 & 0.016 & 0.0020 & 0.0008 & 0.013 & 0.0030 & 0.132 & High sulfur \\
\hline
\end{tabular}

\subsection{Evolution of Inclusions in Liquid Steel}

Figure 4 lists the typical inclusion morphology in Sample S0 of Steel A-C. Figure 4a was MnS inclusion, which was mainly formed during the solidification process of steel. In the present study, although water quenching is conducted as soon as possible after Sample $\mathrm{S} 0$ was extracted, this did not completely avoid the formation of $\mathrm{MnS}$. Figure $4 \mathrm{~b}$ is a Ca-MgAl-Si-Mn-O-S composite inclusion, and this inclusion has a spherical shape, indicating that the inclusion may be liquid in steel. Some literature [45-47] has explained the formation mechanism of Ca-Mg-Al-O inclusion, which is mainly formed in the secondary refining process. In this experiment, $\mathrm{SiO}_{2}$ formed in composite inclusion with the consumption of acid-soluble aluminum by slag-steel reaction during the period from $13 \mathrm{~min}$ to $58 \mathrm{~min}$, and the Ca-Mg-Al-Si-O inclusion formed in steel in final. Figure 4c is a spinel inclusion, which was one of the typical inclusions in Al-killed steel.

Figure 5 shows typical inclusions detected in Sample S1-S2 of Steel A-C. In steel $\mathrm{A}$, after the addition of Ce-Mg lump, it was found that $\mathrm{Ce}-\mathrm{Al}-\mathrm{O}$ inclusions and $\mathrm{Mg}-\mathrm{Al}-$ $\mathrm{O}$ inclusions formed in Sample S1, as shown by A-S1-(a) and A-S1-(b). Cerium reacted with inclusions Ca-Mg-Al-Si-O and transformed into Ce-Ca-Mg-Al-Si-O inclusions, as demonstrated by A-S1-(c). A-S1-(d) showed a novel composite inclusion with a double layer structure: Ce-O-S inclusion was the core inclusion bearing with $\mathrm{Ce}-\mathrm{Ca}-\mathrm{Mg}-\mathrm{Al}-\mathrm{Si}-\mathrm{O}$ inclusions. According to the detection results of Sample S2 of Steel A, the composition of inclusions changed with the continuation of the experiment. The composite inclusion bearing Ce-O-S inclusion (A-S1-(d)) disappeared, while Ce-Al-O inclusions, spinel, Ce-Ca$\mathrm{Mg}-\mathrm{Al}-\mathrm{Si}-\mathrm{O}$ inclusions can still be detected in Sample S2. Besides, (Ca, Mn) S also formed in steel, which is usually considered to be formed during solidification. 

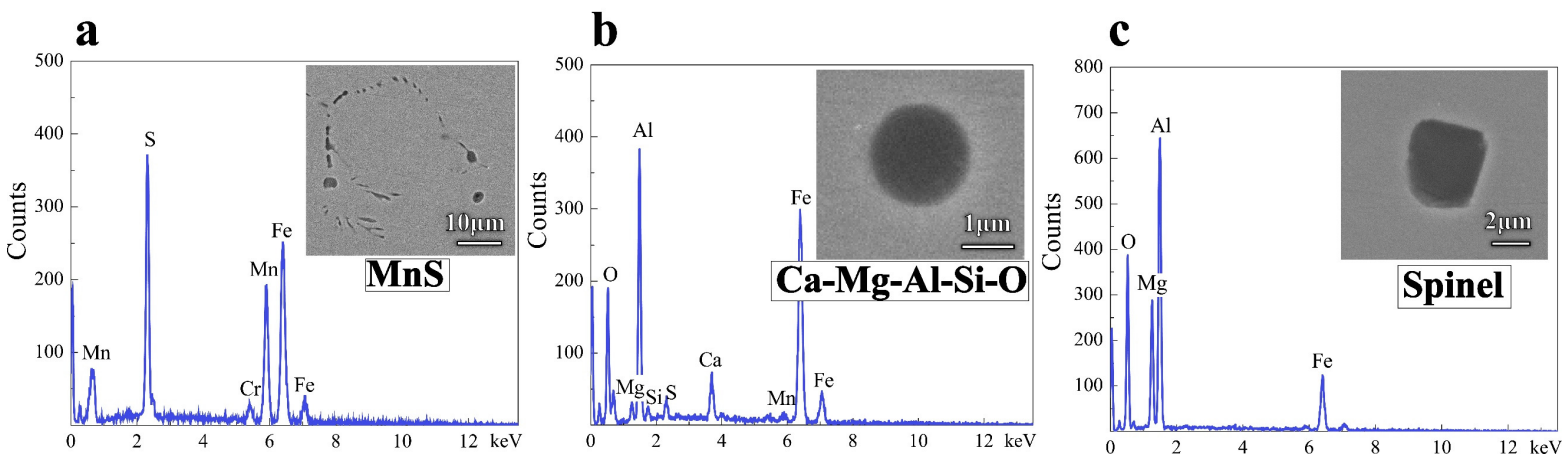

Figure 4. Typical morphology and composition of the inclusions observed in S0 sample. (a) MnS inclusion (b) Ca-Mg-Al-Si-O inclusion (c) Spinel inclusion.

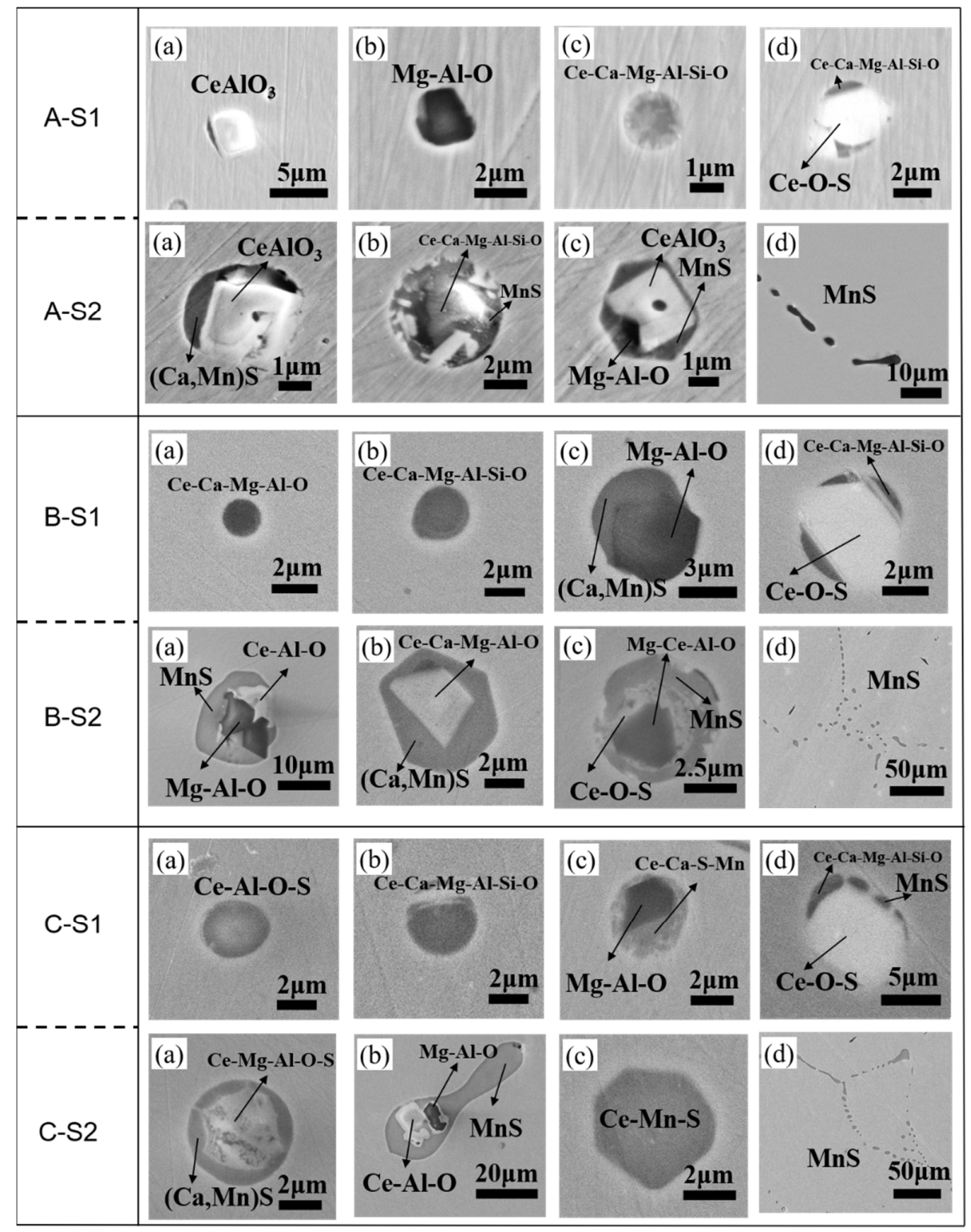

Figure 5. Typical morphology and classification of the inclusions observed in S1-S2 sample. A-S1-(a)A-S1-(d) Inclusion in A-S1. A-S2-(a)-A-S2-(d) Inclusion in A-S2. B-S1-(a)-B-S1-(d) Inclusion in B-S1. B-S2-(a)-B-S2-(d) Inclusion in B-S2. C-S1-(a)-C-S1-(d) Inclusion in C-S1. C-S2-(a)-C-S2-(d) Inclusion in C-S2. 
In Sample S1 of Steel B and Steel C, inclusion types were identical with Steel A. A similar inclusion type exhibited a composite inclusion with a double layer structure: $\mathrm{Ce}-\mathrm{O}-\mathrm{S}$ inclusion serving as a core wrapped by Ce-Ca-Mg-Al-Si-O inclusions can be also found during detection. Typical element mapping of this type of inclusion was shown in Figure 6. With the continuation of the experiment, inclusion with that structure disappeared. However, Ce-O-S inclusion still existed in the composite inclusion as a constituent phase in Sample S2, as shown in B-S2-(c) and C-S2-(a), and this was the main difference from Steel A. In addition, Ce-Mn-S inclusions with a low aspect ratio can be detected only in Steel C, as shown in C-S2-(c).
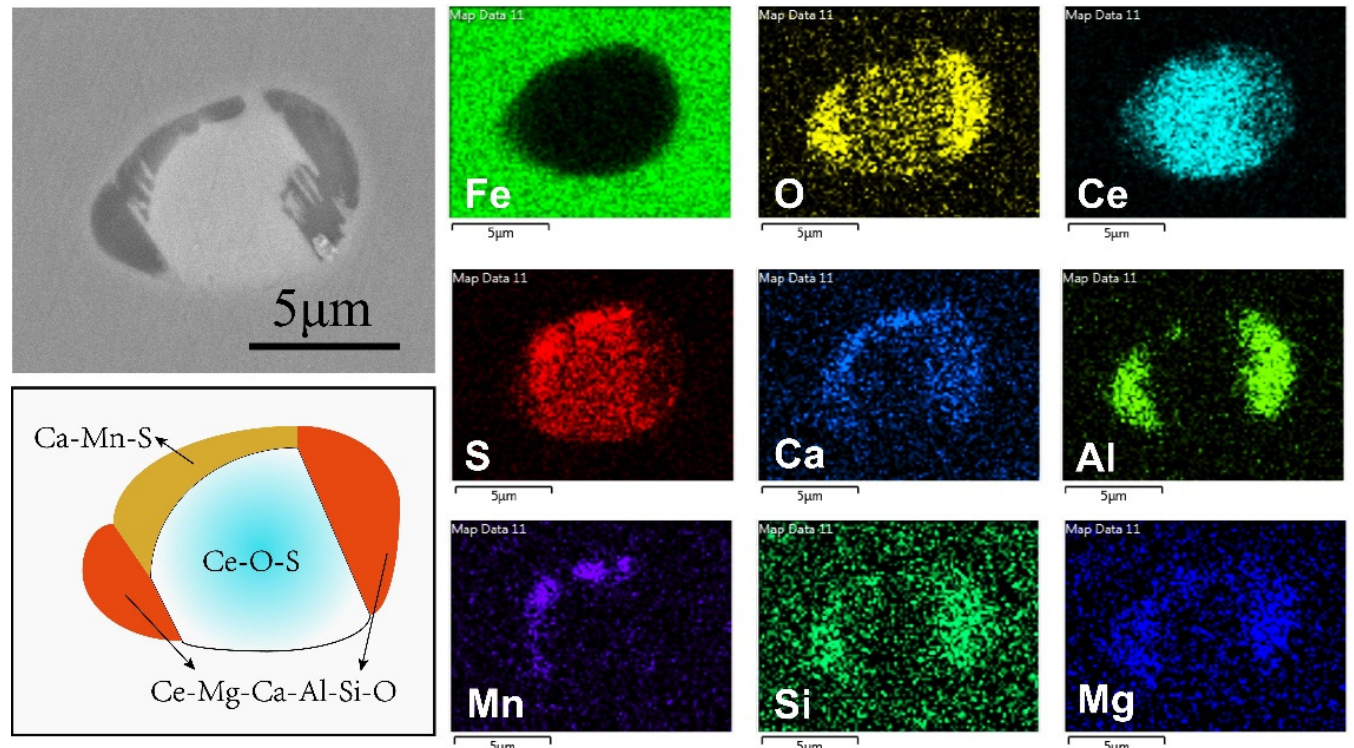

Figure 6. Typical elemental mapping of transition state inclusion in S1 sample for experiments A-C.

Figure 7 presents the proportion of MnS inclusions in Steel A-C. It can be seen that with the increase of sulfur content, the number of MnS inclusions in as-cast samples increased, and the proportion of MnS inclusions in Steel B and C both exceeded 90\%, which was the primary inclusions. Figure 8 shows density, aspect ratio and $\mathrm{D}_{\text {inclusion spacing of }}$ inclusion. With the increase of sulfur content, inclusions density increased, aspect ratio increased, but the inclusion spacing decreased, and their relationship was approximately linear. It indicated that the sulfur content has a significant impact on the MnS precipitation and morphology.

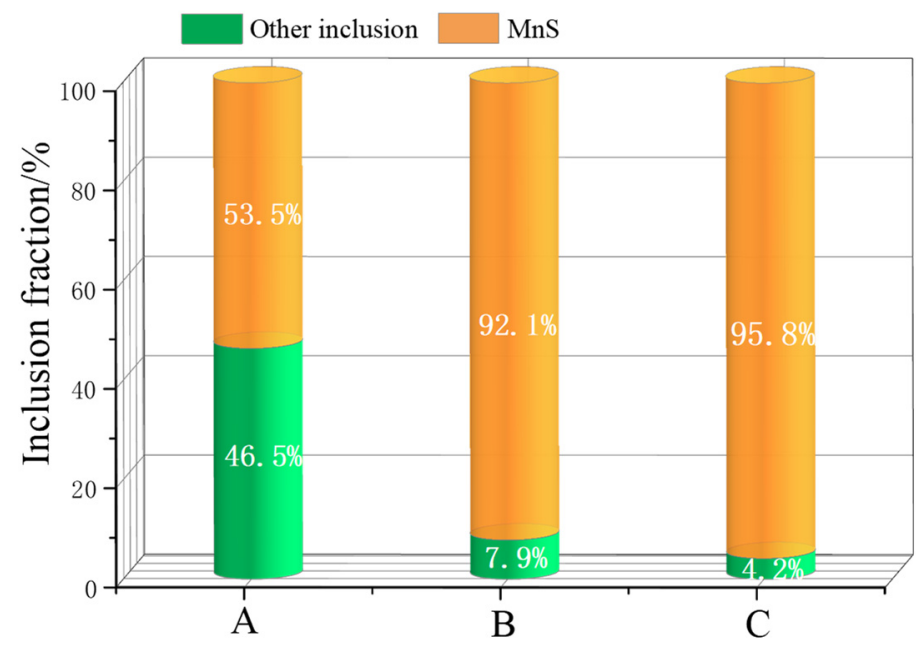

Figure 7. Percentage distribution of inclusion classification in S2 sample for Steel A-C. 

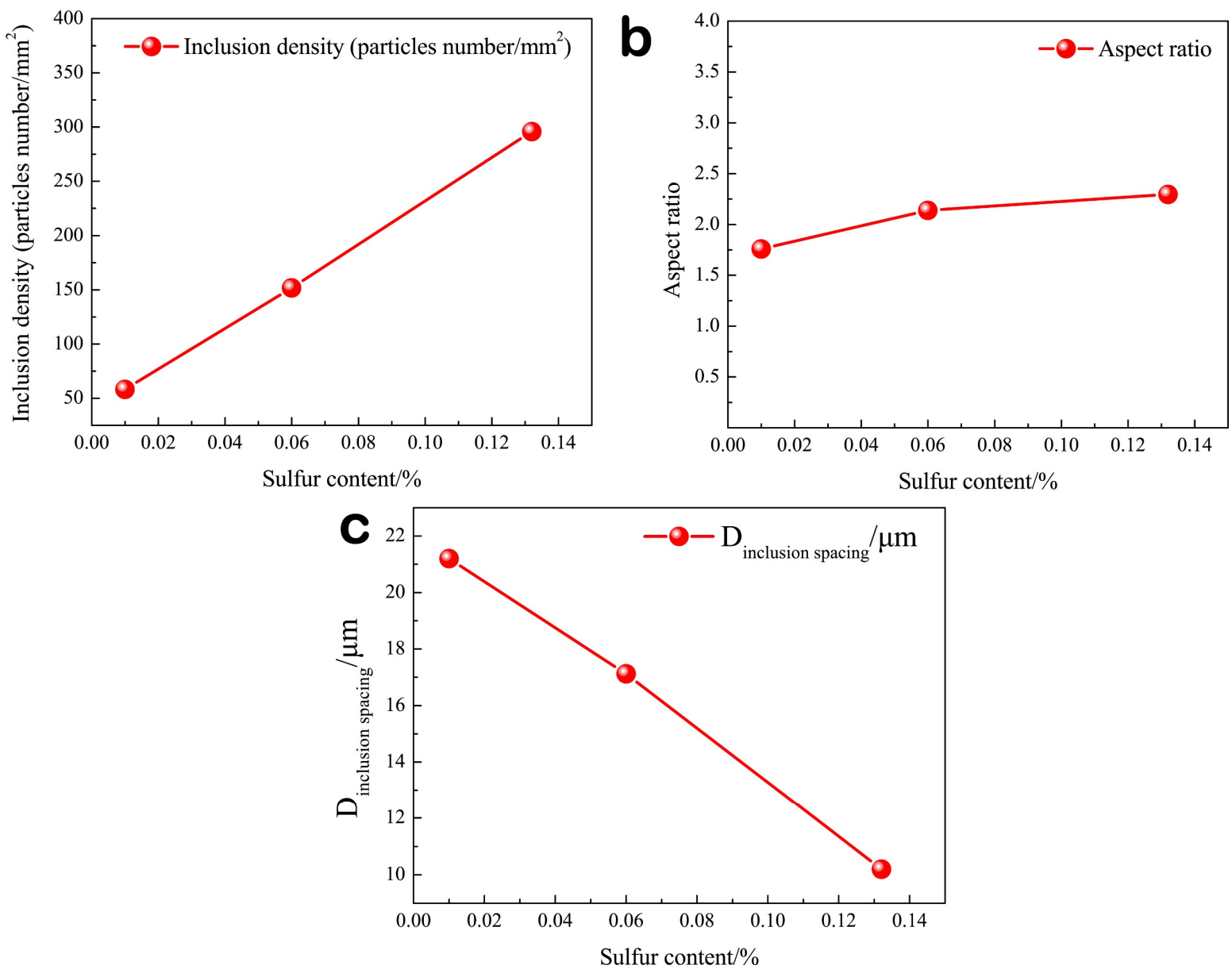

Figure 8. Inclusion density, aspect ratio and $\mathrm{D}_{\text {inclusion spacing }}$ in Sample S2 of Steel A-C. (a) Inclusion density. (b) Aspect ratio. (c) $\mathrm{D}_{\text {inclusion spacing. }}$.

A summary of the phenomenon that the sulfur content has an impact on inclusion evolution in liquid steel at $1873 \mathrm{~K}$ and $\mathrm{MnS}$ inclusion precipitation during solidification can be obtained as follows, a type of double structure inclusion that Ce-O-S inclusion serving as a core wrapped by $\mathrm{Ce}-\mathrm{Ca}-\mathrm{Mg}-\mathrm{Al}-\mathrm{Si}-\mathrm{O}$ inclusions can form in liquid steel after $\mathrm{Ce}-\mathrm{Mg}$ lump addition and disappeared with experiment time prolonging. In Sample S2, Ce-O-S inclusion can not be detected in Steel A but can be found in Steel B and Steel C. The increase of sulfur content promotes MnS precipitation and also has an impact on the $\mathrm{D}_{\text {inclusion spacing }}$ and morphology of MnS.

\subsection{Discussion on Evolution Mechanism of Inclusions in Liquid Steel}

To illustrate the inclusion mechanism in liquid steel after Ce-Mg lump addition, a thermodynamic calculation was conducted by FactSage software. Database was selected as FactPS and FSstel, and the system was $0.20 \mathrm{C}-0.30 \mathrm{Si}-0.87 \mathrm{Mn}-0.02 \mathrm{Al}-0.001 \mathrm{Mg}-$ $0.0020 \mathrm{Ca}-0.003 \mathrm{O}-1.20 \mathrm{Cr}-\mathrm{S}-\mathrm{Ce}-\mathrm{Fe}$ (balance). It can be seen from Figure 9, the results showed that with the increase of cerium content, the evolution sequence of Ce-containing inclusions in $0.01 \%$ sulfur content steel was $\mathrm{CeAlO}_{3} \rightarrow \mathrm{Ce}_{2} \mathrm{O}_{3} \rightarrow \mathrm{Ce}_{2} \mathrm{O}_{2} \mathrm{~S}$, and the evolution sequence of Ce-containing inclusions in $0.06 \%$ and $0.132 \%$ sulfur content steel was $\mathrm{CeAlO}_{3} \rightarrow \mathrm{Ce}_{2} \mathrm{O}_{2} \mathrm{~S} \rightarrow \mathrm{Ce}_{2} \mathrm{~S}_{3}$. When cerium content was fixed as $0.013 \%$, the variation of cerium-containing inclusions was $\mathrm{CeAlO}_{3} \rightarrow \mathrm{Ce}_{2} \mathrm{O}_{2} \mathrm{~S}$ with the increase of sulfur content. From here, it can be concluded that the increase of cerium content and sulfur content can both result in the transition between $\mathrm{CeAlO}_{3}$ and $\mathrm{Ce}_{2} \mathrm{O}_{2} \mathrm{~S}$. 

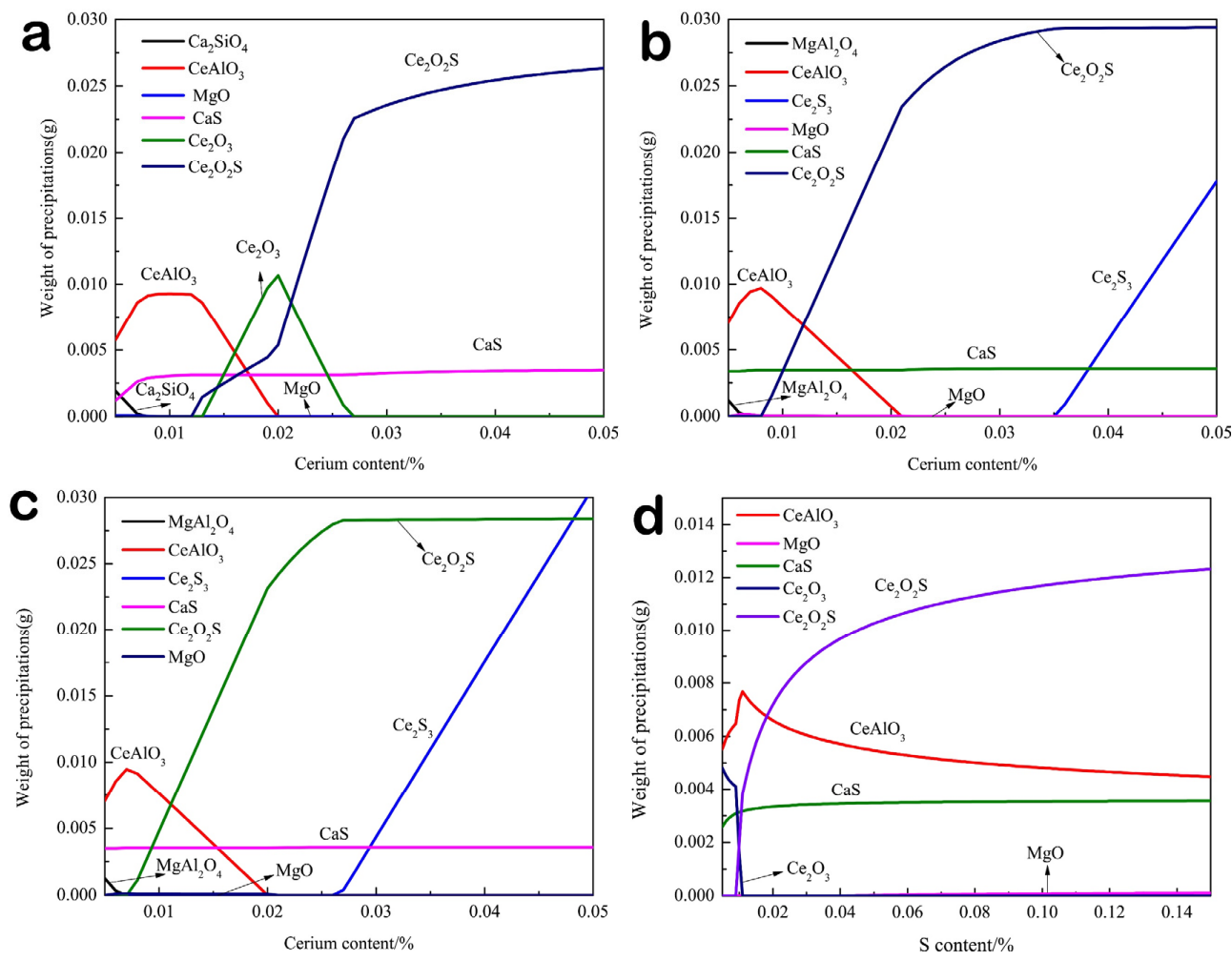

Figure 9. Thermodynamic calculation of the effect of cerium content and sulfur content on inclusion formation by FactSage. (a) Effect of Ce content on inclusion formation in steel containing $0.01 \%$ sulfur content (b) Effect of Ce content on inclusion formation in steel containing $0.06 \%$ sulfur content (c) Effect of Ce content on inclusion formation in steel containing $0.132 \%$ sulfur content (d) Effect of $\mathrm{S}$ content on inclusion formation in steel containing $0.013 \%$ Ce content.

Based on experimental results and thermodynamic calculation results, the inclusion evolution mechanism for this research was concluded as shown in Figure 10. In a short time after adding the Ce-Mg lump, due to the limitation of mass transfer, there was a concentrated area of cerium in liquid steel. Considering thermodynamic calculations, the high content of cerium in the concentrated area resulted in the formation of $\mathrm{Ce}_{2} \mathrm{O}_{2} \mathrm{~S}$. At the same time, the addition of magnesium can bring a severe stirring of the molten pool because the solubility of magnesium in liquid steel is very low, resulting in the probability of physical collision of inclusion increasing greatly. Under this system conditions, a comprehensible situation is that $\mathrm{Ce}_{2} \mathrm{O}_{2} \mathrm{~S}$, as a high melting point inclusion, presents a solid-state in liquid steel, and collides with $\mathrm{Ca}-\mathrm{Mg}$-Al-Si-O inclusion in a liquid state. As a result, the liquid phase adhered to the outside of the solid phase and formed a composite inclusion with a double-layer structure, as shown in A-S1-(d), B-S1-(d), C-S1-(d) in Figure 5. Considering that formation mechanism and experimental phenomenon, this inclusion was named transition state inclusion. With the homogenization of steel and conduct of chemical reactions, in Steel A, due to the $\mathrm{CeAlO}_{3}$ has higher formation ability than $\mathrm{Ce}_{2} \mathrm{O}_{2} \mathrm{~S}, \mathrm{Ce}_{2} \mathrm{O}_{2} \mathrm{~S}$ phase of transition state inclusion transition into $\mathrm{CeAlO}_{3}$ as expressed in reaction (1).

$$
\mathrm{Ce}_{2} \mathrm{O}_{2} \mathrm{~S}+2[\mathrm{Al}]+4[\mathrm{O}]=2 \mathrm{CeAlO}_{3}+[\mathrm{S}]
$$




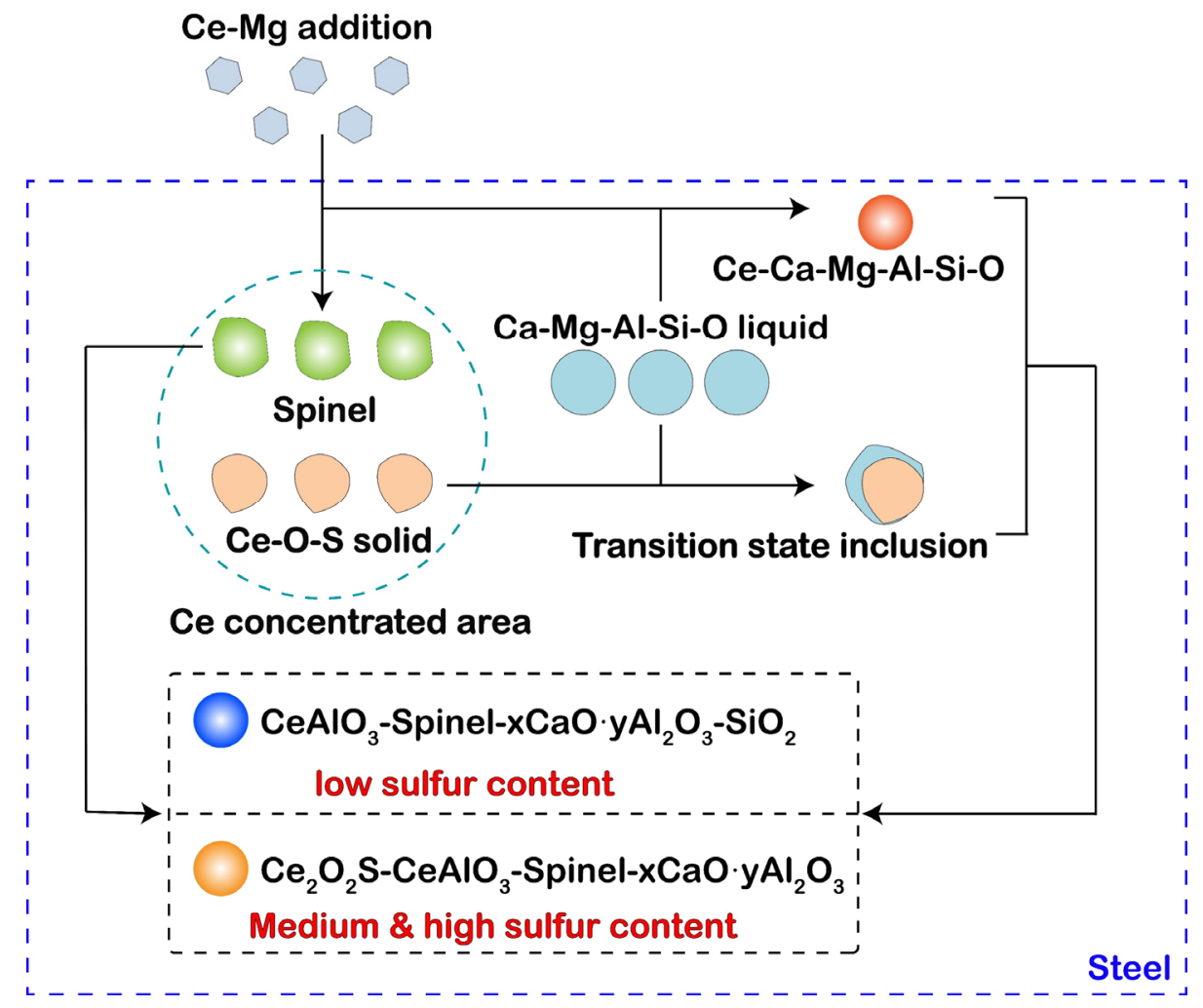

Figure 10. Schematic diagram of inclusion evolution after $\mathrm{Ce}-\mathrm{Mg}$ addition.

In Steel $\mathrm{B}$ and Steel $\mathrm{C}$, the formation ability of $\mathrm{Ce}_{2} \mathrm{O}_{2} \mathrm{~S}$ is stronger than $\mathrm{CeAlO}_{3}$. Therefore, Ce-O-S of transition state inclusion was not replaced, and as the substitution reaction conducting at the outer layer, $\mathrm{SiO}_{2}$ and $\mathrm{CaO}$ in the outer layer were consumed according to reaction (2)-(5), which can be seen as B-S2-(c) and C-S2-(a).

$$
\begin{gathered}
4[\mathrm{Ce}]+2\left(\mathrm{Al}_{2} \mathrm{O}_{3}\right)_{\text {inclusion }}+3\left(\mathrm{SiO}_{2}\right)_{\text {inclusion }}=4 \mathrm{CeAlO}_{3}+3[\mathrm{Si}] \\
2[\mathrm{Ce}]+\left(\mathrm{Al}_{2} \mathrm{O}_{3}\right)_{\text {inclusion }}+3(\mathrm{CaO})_{\text {inclusion }}=2 \mathrm{CeAlO}_{3}+3[\mathrm{Ca}] \\
2[\mathrm{Ce}]+\left(\mathrm{SiO}_{2}\right) \text { inclusion }+[\mathrm{S}]=\mathrm{Ce}_{2} \mathrm{O}_{2} \mathrm{~S}+[\mathrm{Si}] \\
2[\mathrm{Ce}]+2(\mathrm{CaO})_{\text {inclusion }}+[\mathrm{S}]=\mathrm{Ce}_{2} \mathrm{O}_{2} \mathrm{~S}+2[\mathrm{Ca}]
\end{gathered}
$$

Also, based on the experimental phenomena, there were two reactions conducted in liquid steel as follows, (1) Cerium reacted directly with aluminum and oxygen to form $\mathrm{CeAlO}_{3}$ in liquid steel. (2) Cerium reacted with the Ca-Mg-Al-O inclusion forming before adding Ce-Mg lump with the consumption of the unstable oxide components (such as $\mathrm{SiO}_{2}$ ) and forming composite inclusion Ce-Ca-Mg-Al-Si-O.

\subsection{Precipitation of MnS Inclusion during Solidification}

The three-dimensional morphology of MnS observed by SEM was presented in Figure 11a-1. It is obviously that the size of MnS inclusion has become much more extensive and the morphology of MnS has become from "stick" to "dendritic + fishbone" to "fishbone" with the increase of sulfur content. Especially, MnS inclusions showed a multi-directional growth morphology in Steel C, which is consistent with the analysis in two-dimensional morphology. 

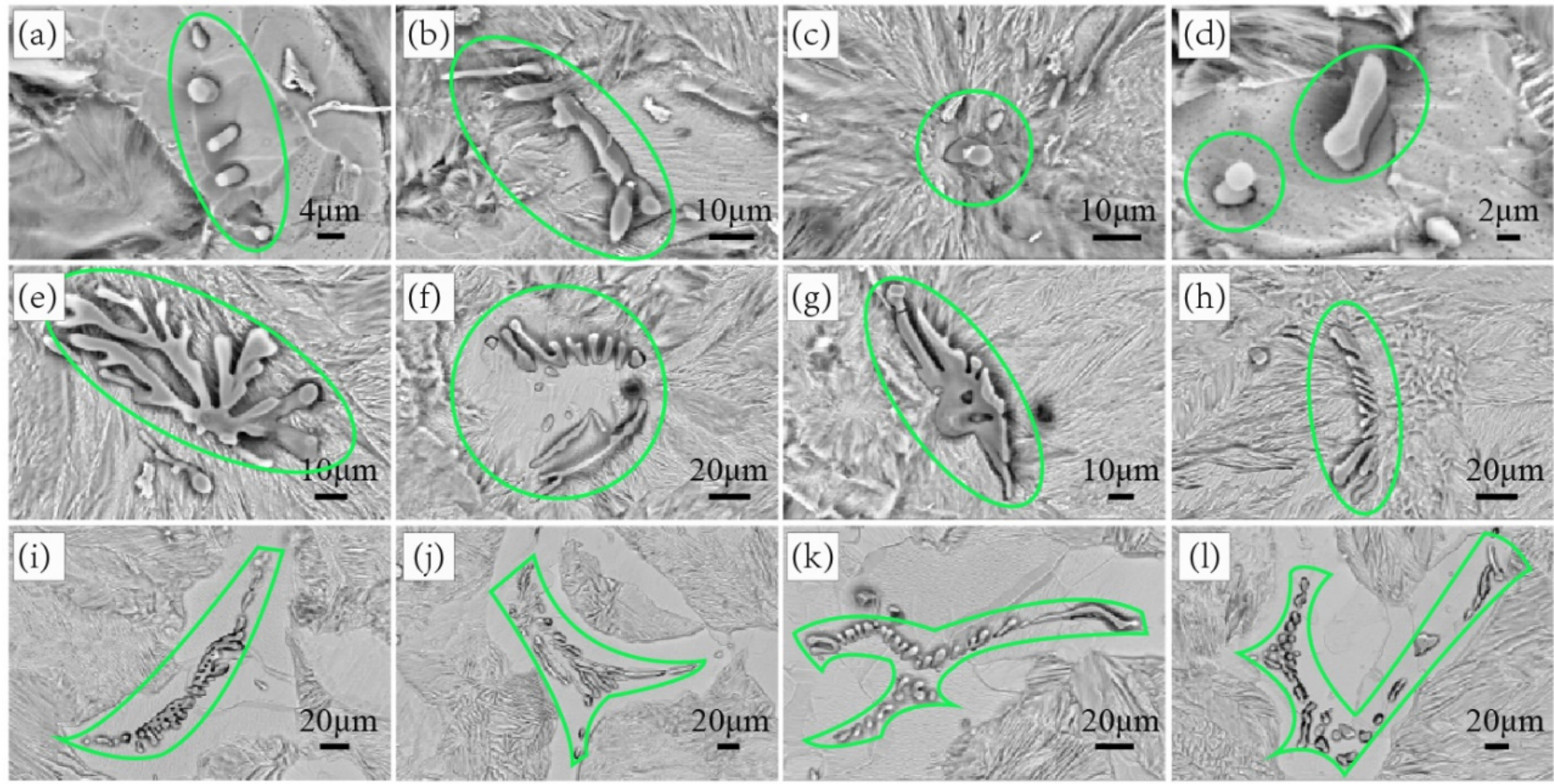

Figure 11. 3D morphology of MnS inclusions in as-cast sample. (a-d) Sample S2 of Steel A; (e-h) Sample S2 of Steel B; (i-1) Sample S2 of Steel C.

For understanding the precipitation behavior of MnS, in the present study, FactSage software was used to analyze the precipitation behavior of MnS during solidification under different sulfur contents. The calculation was based on the Scheil-Gulliver model [48] which assumes that no diffusion takes place in the solid and that solute redistribution in the liquid is fast. The database were FactPS and FSstel, and the calculation system is $0.20 \mathrm{C}-0.30 \mathrm{Si}$ $0.87 \mathrm{Mn}-0.02 \mathrm{Al}-0.001 \mathrm{Mg}-0.0020 \mathrm{Ca}-0.003 \mathrm{O}-1.20 \mathrm{Cr}-\mathrm{S}-0.013 \mathrm{Ce}-\mathrm{Fe}$ (balance). The calculation results were shown in Figure 12. With the increase of sulfur content, the temperature point at which MnS precipitated in large quantities advances during solidification. The increase of sulfur content resulted in the increase of the mass fraction of MnS obviously, and when the sulfur content reached $0.132 \%$, the mass fraction of MnS in the system reached $0.21 \%$.

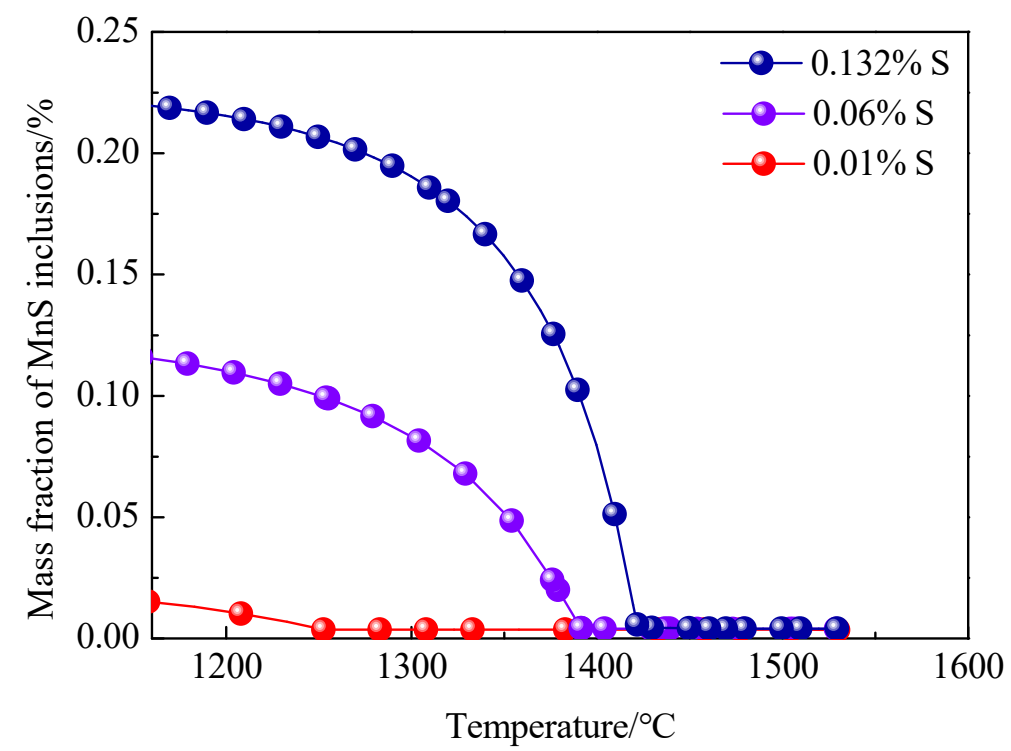

Figure 12. Thermodynamic calculation of MnS inclusion formation during solidification process by FactSage. 


\subsection{Effects of MnS Inclusions on Mechanical Properties}

Figure 13 presents the tensile strength and elongation of Steel A-C. It can be seen that with the increase of sulfur content, tensile strength and elongation showed a downward trend. Tensile strength decreased from 1443.8 MP to $1343.57 \mathrm{MPa}$, and the elongation decreased from $9.7 \%$ to $6.8 \%$. The negative effect of the increase of sulfur content on the strength and ductility of steel was noticeable.
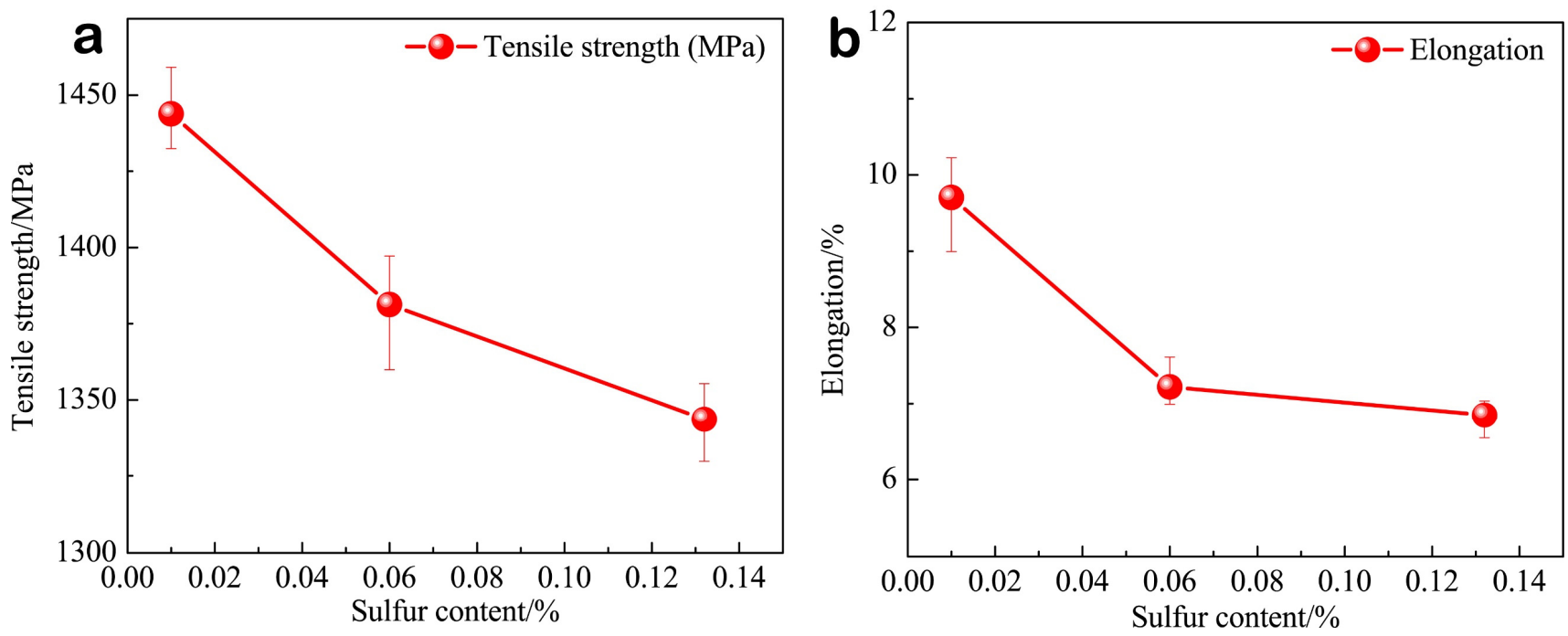

Figure 13. Tensile strength and elongation result. (a) Tensile strength; (b) Elongation.

To explore the impact mechanism of sulfur content on tensile fracture, the fracture morphology of Steel A-C was observed and analyzed. Representative fractography of tensile specimens was presented in Figure 14. According to Figure 14a-i, the fracture morphology consisted of major cracks, voids, and dimples. With the increase of sulfur content, the void amount increased obviously, and the morphology that multiple voids coalescenced into large-sized voids can be observed clearly in Steel $C$ as shown in Figure 14i. $\mathrm{MnS}$ inclusion can be found in some voids, which indicates that MnS inclusion provided a nucleation point for void initiation. Figure 14j-l present the observation and analysis of the longitudinal section of the tensile fracture. It can be seen that MnS inclusion located at the root of a void. It can be inferred that stress concentration occurs at the tip of MnS, which resulted in void initiation. This is consistent with the research of Yamamoto et al. [49].

The fracture of steel was usually illustrated as void nucleation, growth, coalescence. As the nucleation point of the void, the distance between inclusions may greatly determine the difficulty of void coalescence. In the present study, the increase of sulfur content caused the decline of inclusion spacing and resulted in a shorter physical path of crack propagation in steel, which makes void coalescence occurrence easier. A schematic diagram of this mechanism was presented in Figure $14 \mathrm{~m}$.

For the purpose of machinability enhancement, the sulfur content of gear steel $\mathrm{SCr} 420 \mathrm{H}$ is considered to increase in the future. The volume of MnS will increase a lot in steel because of the increase of sulfur content. Excessive MnS inclusion can increase the nucleation points of cracks inevitably and bring a harmful effect on the mechanical properties of steel. Therefore, it is essential to adopt some metallurgical means to make MnS distribute uniformly, and the damage of inclusions to mechanical properties can be suppressed. 

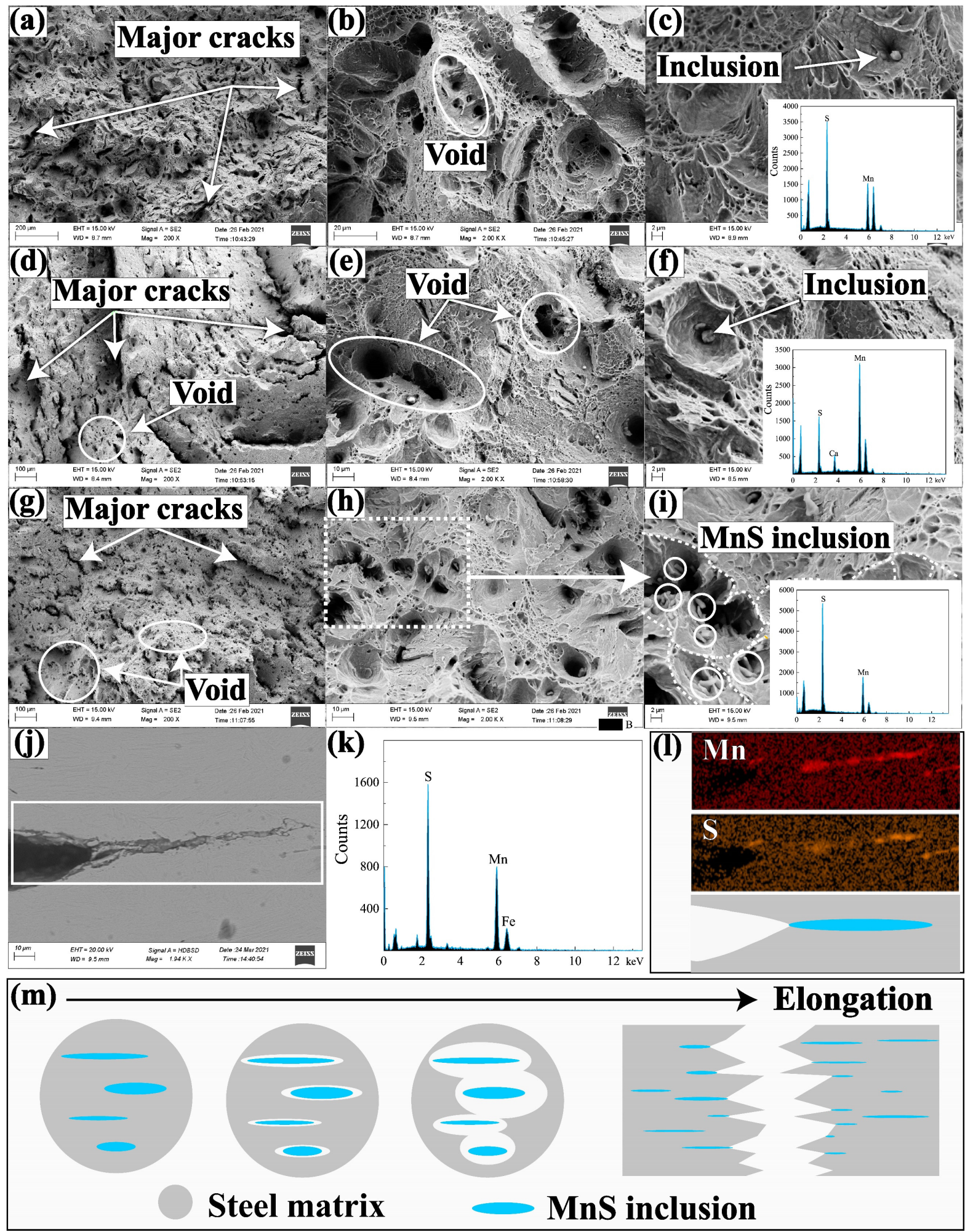

Figure 14. Morphology observation and inclusion analysis on tensile fracture. $(\mathbf{a}-\mathbf{c})$ tensile fracture of Steel A; $(\mathbf{d}-\mathbf{f})$ tensile fracture of Steel B; $(\mathbf{g}-\mathbf{i})$ tensile fracture of Steel C; $(\mathbf{j}-\mathbf{l})$ Longitudinal section of tensile fracture of Steel $C_{;}(\mathbf{m})$ Schematic diagram of MnS inclusion initiation fracture.

\section{Conclusions}

The current work investigated the effect of sulfur content on inclusion and mechanical properties by laboratory experiment and thermodynamic calculation. The main conclusions were summarized as follows. 
(1) After the Ce-Mg addition, the cerium concentration area formed in liquid steel. This may result in the formation of transition state inclusions. In current experiment, solid $\mathrm{Ce}_{2} \mathrm{O}_{2} \mathrm{~S}$ formed in the cerium concentration area and collides with Ca-Mg$\mathrm{Al}-\mathrm{Si}-\mathrm{O}$ liquid inclusion, and the liquid phase adhered to the outside of the solid phase, and formed a composite inclusion with a double-layer structure. As a type of transition state inclusion, it only exists in a short time after Ce-Mg addition. As the homogenization of liquid steel, cerium concentration area disappeared, and the difference of sulfur content in steel can result in this type of transition state inclusions transformed into different inclusions.

(2) The thermodynamic calculation results indicated that with the increase of cerium content, the evolution sequence of Ce-containing inclusions in $0.01 \%$ sulfur content steel is $\mathrm{CeAlO}_{3} \rightarrow \mathrm{Ce}_{2} \mathrm{O}_{3} \rightarrow \mathrm{Ce}_{2} \mathrm{O}_{2} \mathrm{~S}$, and the evolution sequence of Ce-containing inclusions in $0.06 \%$ and $0.132 \%$ sulfur content steel is $\mathrm{CeAlO}_{3} \rightarrow \mathrm{Ce}_{2} \mathrm{O}_{2} \mathrm{~S} \rightarrow \mathrm{Ce}_{2} \mathrm{~S}_{3}$.

(3) With the sulfur content increasing from $0.01 \%$ to $0.132 \%$, MnS becomes the prominent inclusion in steel, and inclusion spacing decreases from $21.20 \mu \mathrm{m}$ to $10.19 \mu \mathrm{m}$, the tensile strength decreases from $1443.8 \mathrm{MPa}$ to $1343.57 \mathrm{MPa}$, and the elongation decreases from $9.7 \%$ to $6.8 \%$.

Author Contributions: Conceptualization, M.S. and Z.J.; Methodology, M.S. and Y.L.; Formal analysis, M.S. and S.M.; Writing, M.S., Y.J. and J.W.; Resources, C.C. and H.L. All authors have read and agreed to the published version of the manuscript.

Funding: This work was supported by the National Natural Science Foundation of China N. 52074075 and the National Key Research and Development Program of China N. 2016YFB0300105.

Institutional Review Board Statement: Not applicable.

Informed Consent Statement: Not applicable.

Data Availability Statement: Not applicable.

Conflicts of Interest: The authors declare no conflict of interest.

\section{References}

1. Xie, J.B.; Zhang, D.; Yang, Q.K.; An, J.M.; Huang, Z.Z.; Fu, J.X. Exploration of morphology evolution of the inclusions in Mg-treated 16MnCrS5 steel. Ironmak. Steelmak. 2019, 46, 564-573. [CrossRef]

2. Sun, H.; Wu, L.P.; Xie, J.B.; Ai, K.N.; Zeng, Z.Q.; Shen, P.; Fu, J.X. Inclusions modification and improvement of machinability in a non-quenched and tempered steel with Mg treatment. Metall. Res. Technol. 2020, 117, 208. [CrossRef]

3. Ånmark, N.; Karasev, A.; Jönsson, P.G. The effect of different non-metallic inclusions on the machinability of steels. Materials 2015, 8, 751-783. [CrossRef]

4. Sui, H.; Wang, L.J; Wang, Q.; Wang, H.M.; Che, D.H.; Li, J.M. The formation and growth of sulfides in free-cutting stainless steel. Steel Res. Int. 2018, 89, 1800179. [CrossRef]

5. Ånmark, N.; Karasev, A.; Jönsson, P.G. The influence of microstructure and non-metallic inclusions on the machinability of clean steels. Steel Res. Int. 2017, 88, 1600111. [CrossRef]

6. An, X.X.; Tian, Y.; Wang, H.J.; Shen, Y.F.; Wang, Z.D. Suppression of austenite grain coarsening by using Nb-Ti microalloying in high temperature carburizing of a gear steel. Adv. Eng. Mater. 2019, 21, 1900132. [CrossRef]

7. An, X.X.; Tian, Y.; Wang, H.J.; Wang, Z.D. Effect of preheat treatment on microstructure and properties of a gear steel for high-temperature carburizing. Steel Res. Int. 2020, 91, 2000180. [CrossRef]

8. Wen, B.; Song, B.; Pan, N.; Hu, Q.Y.; Mao, J.H. Effect of austenitizing temperature on microstructure in $16 \mathrm{Mn}$ steel treated by cerium. Int. J. Miner. Metall. Mater. 2011, 18, 652-658. [CrossRef]

9. Ji, Y.P.; Zhang, M.X.; Ren, H.P. Roles of lanthanum and cerium in grain refinement of steels during solidification. Metals 2018, 8 , 884. [CrossRef]

10. Ji, Y.P.; Li, Y.M.; Zhang, M.X.; Qu, W.; Zhao, T.X.; Ren, H.P. Grain refinement mechanism of the $\delta$-ferrite in steels through cerium addition. Metall. Mater. Trans. A 2020, 51, 1707-1718. [CrossRef]

11. Jiang, X.; Song, S.H. Enhanced hot ductility of a Cr-Mo low alloy steel by rare earth cerium. Mater. Sci. Eng. A 2014, 613, 171-177. [CrossRef]

12. Gao, J.Z.; Fu, P.X.; Liu, H.W.; Li, D.Z. Effects of rare earth on the microstructure and impact toughness of H13 steel. Metals 2015, 5, 383-394. [CrossRef]

13. Jiang, Z.H.; Wang, C.; Gong, W.; Wang, H.D. Evolution of inclusions and change of as-cast microstructure with Mg addition in high carbon and high chromium die steel. Ironmak. Steelmak. 2015, 42, 669-674. [CrossRef] 
14. Cui, X.K.; Song, B.; Yang, Z.B.; Liu, Z.; Li, L.F.; Wang, L. Effect of Mg on the evolution of inclusions and formation of acicular ferrite in La-Ti-treated steels. Steel Res. Int. 2020, 91, 1900563. [CrossRef]

15. Jiang, Z.H.; Xu, G.; Li, Y.; Li, H.B.; Lv, J.B.; Wang, Q. Effect of ultra-high magnesium on SKS51 liquid steel cleanliness and microstructure. ISIJ Int. 2019, 59, 1234-1241. [CrossRef]

16. Bao, D.H.; Cheng, G.G.; Huang, Y.; Qiao, T.; Dai, W.X. Refinement of Solidification Structure of H13 Steel by Rare Earth Sulfide. Steel Res. Int. 2021, 93, 2100304. [CrossRef]

17. Shin, J.H.; Park, J.H. Formation mechanism of oxide-sulfide complex inclusions in high-sulfur containing steel melts. Metall. Mater. Trans. A 2017, 49, 311-324. [CrossRef]

18. Li, X.; Long, X.; Wang, L.; Tong, S.; Wang, X.; Zhang, Y.; Li, Y. Inclusion characteristics in 95CrMo steels with different calcium and sulfur contents. Materials 2020, 13, 619. [CrossRef]

19. Zeng, J.; Zhu, C.Y.; Wang, W.L.; Li, X. In situ observation of the MnS precipitation behavior in high-sulfur microalloyed steel under different cooling rates. Metall. Mater. Trans. B 2020, 51, 2522-2531. [CrossRef]

20. Maciejewski, J. The effects of sulfide inclusions on mechanical properties and failures of steel components. J. Failure Anal. Prev. 2015, 15, 169-178. [CrossRef]

21. Huang, Y.; Cheng, G.G.; Li, S.J.; Dai, W.X. Effect of cerium on the behavior of inclusions in H13 steel. Steel Res. Int. 2018, 89, 1800371. [CrossRef]

22. Ren, Q.; Zhang, L.F. Effect of cerium content on inclusions in an ultra-low-carbon aluminum-killed steel. Metall. Mater. Trans. B 2020, 51, 589-600. [CrossRef]

23. Hamidzadeh, M.A.; Meratian, M.; Saatchi, A. Effect of cerium and lanthanum on the microstructure and mechanical properties of AISI D2 tool steel. Mater. Sci. Eng. A 2013, 571, 193-198. [CrossRef]

24. Lin, C.K.; Pan, Y.C.; Su, Y.H.F.; Lin, G.R.; Hwang, W.S.; Kuo, J.C. Effects of Mg-Al-O-Mn-S inclusion on the nucleation of acicular ferrite in magnesium-containing low-carbon steel. Mater. Charact. 2018, 141, 318-327. [CrossRef]

25. Du, G.; Li, J.; Wang, Z.B.; Shi, C.B. Effect of magnesium addition on behavior of collision and agglomeration between solid inclusion particles on $\mathrm{H} 13$ steel meltes. Steel Res. Int. 2017, 88, 1600185. [CrossRef]

26. Wang, H.; Li, J.; Shi, C.B.; Li, J. Eolution of $\mathrm{Al}_{2} \mathrm{O}_{3}$ inclusions by magnesium treatment in $\mathrm{H} 13$ hot work die steel. Ironmak. Steelmak. 2016, 44, 128-133. [CrossRef]

27. Huang, Y.; Cheng, G.G.; Xie, Y. Modification Mechanism of Cerium on the Inclusions in Drill Steel. Acta Metall. Sin. 2018, 54, $1253-1261$.

28. Roos, E.; Karasev, A.; Jönsson, P.G. Effect of Si and Ce contents on the nozzle clogging in a REM alloyed stainless steel. Steel Res. Int. 2015, 86, 1279-1288. [CrossRef]

29. Shen, P.; Fu, J. Morphology study on inclusion modification using Mg-Ca treatment in resulfurized special steel. Materials 2019, 12, 197. [CrossRef] [PubMed]

30. Li, X. Metallurgical Quality and Composition Optimization of H13 Hot Work Die Steel. Ph.D. Thesis, Northeastern University, Shenyang, China, 2020.

31. Luyckx, L.; Bell, J.R.; Mclean, A.; Korchynsky, M. Sulfide Shape Control in High Strength Low Alloy Steels. Metall. Trans. 1970, 1 , $3341-3350$

32. Dahl, W.; Gammal, T.E.; Lorenz, L.L. Einfluß sehr niedriger Schwefelgehalte auf die mechanischen Eigenschaften des Stahles St 52-3. Arch. Eisenhüttenwesen 1973, 44, 843-846. [CrossRef]

33. Banks, T.M.; Gladman, T. Sulphide shape control. Met. Technol. 1979, 6, 81-94. [CrossRef]

34. Handerhan, K.J.; Garrison, W.M.; Moody, N.R. A Comparison of the Fracture Behavior of Two Heats of the Secondary Hardening Steel AF1410. Metall. Trans. A 1989, 20, 105-123. [CrossRef]

35. Li, X.; Jiang, Z.H.; Geng, X.; Chen, M.J.; Cui, S. Effect of rare earth-magnesium alloy on inclusion evolution in industrial production of die steel. Steel Res. Int. 2019, 90, 1900103. [CrossRef]

36. Li, X.; Jiang, Z.H.; Geng, X.; Chen, M.J.; Peng, L.Z. Evolution mechanism of inclusions in H13 steel with rare earth magnesium alloy addition. ISIJ Int. 2019, 59, 1552-1561. [CrossRef]

37. Chang, L.Z.; Gao, G.; Zheng, F.Z.; Shi, X.F. Effect of rare earth and magnesium complex treatment on inclusions in GCr15 bearing steel. J. Chem. Eng. 2019, 41, 763-771.

38. Maloney, J.L.; Garrison, W.M. The effect of sulfide type on the fracture behavior of HY180 steel. Acta Mater. 2005, 53, 533-551. [CrossRef]

39. Ma, Y.; Pan, T.; Jiang, B.; Cui, Y.H.; Su, H.; Peng, Y. Study of the effect of sulfur contents on frature toughness on railway wheel steels for high speed train. Acta Metall. Sin. 2011, 47, 978-983.

40. Yang, C.Y.; Luan, Y.K.; Li, D.Z.; Li, Y.Y. Very hgih cycle fatigue properties of bearing steel with different aluminum and sulfur content. Int. J. Fatigue 2018, 116, 396-408. [CrossRef]

41. Kang, M.H.; Lee, J.S.; Koo, Y.M.; Kim, S.J.; Heo, N.H. Correlation between MnS precipitation, sulfur segregation kinetics, and hot ductility in C-Mn steel. Metall. Mater. Trans. A 2014, 45, 5295-5299. [CrossRef]

42. Oikawa, K.; Ohtani, H.; Ishida, K.; Nishizawa, T. The control of the morphology of MnS inclusions in steel during solidification. ISIJ Int. 1995, 4, 402-408. [CrossRef]

43. Wijk, O.; Brabie, V. The purity of ferrosilicon and its influence on inclusion cleanliness of steel. ISIJ Int. 1996, 36, 132-135. [CrossRef] 
44. Mizuno, K.; Todoroki, H.; Noda, M.; Tohge, T. Effects of Al and Ca in ferrosilicon alloys for deoxidation on inclusion composition in type 304 stainless steel. Iron Steelmak. 2001, 28, 93-101.

45. Deng, Z.Y.; Zhu, M.Y. Evolution mechanism of non-metallic inclusions in Al-killed alloyed steel during secondary refining process. ISIJ Int. 2013, 53, 450-458. [CrossRef]

46. Liu, C.Y.; Huang, F.X.; Wang, X.H. The effect of refining slag and refractory on inclusion transformation in extra low oxygen steels. Metall. Mater. Trans. B 2016, 47, 999-1009. [CrossRef]

47. Jiang, M.; Wang, X.H.; Chen, B.; Wang, W.J. Laboratory study on evolution mechanisms of non-metallic inclusions in high strength alloyed steel refined by high basicity slag. ISIJ Int. 2010, 50, 95-104. [CrossRef]

48. Gulliver, G.H. The quantitative effect of rapid cooling upon the constitution of binary alloys. J. Inst. Met. 1913, 9, $120-157$.

49. Yamamoto, K.I.; Yamamura, H.; Suwa, Y. Behavior of non-metallic inclusions in steel during hot deformation and the effects of deformed inclusions on local ductility. ISIJ Int. 2011, 12, 1987-1994. [CrossRef] 